\title{
ARTIGO
}

do1 https://doi.org/10.22481/praxisedu.v16i41.6513

\section{A ESCOLA PÚBLICA E O CURRÍCULO COMO CRIAÇÃO COTIDIANA: A VISIBILIZAÇÃO DAS POLÍTICASPRÁTICAS DE SAÚDE}

\author{
PUBLIC SCHOOL AND THE CURRICULUM AS EVERYDAY CREATION: THE \\ VISIBILIZATION OF HEALTH POLICIESPRACTICES
}

\section{LA ESCUELA PÚBLICA Y EL CURRÍCULO COMO CREACIÓN COTIDIANA: LA VISIBILIDAD DE LAS POLÍTICAS PRÁCTICAS DE SALUD}

\author{
Cinthia Emerenciana de Almeida \\ Centro Universitário de Volta Redonda - Brasil \\ Alexandre Palma de Oliveira \\ Universidade Federal do Rio de Janeiro - Brasil \\ Marcelo Paraiso Alves \\ Centro Universitário de Volta Redonda - Brasil \\ Instituto Federal do Rio de janeiro - Brasil
}

\begin{abstract}
Resumo: O presente trabalho possui gênese em uma dissertação de mestrado profissional na área de saúde e meio ambiente e se caracteriza como uma proposição didática para a discussão de saúde junto à Educação de Jovens e Adultos (EJA). A referida proposição pedagógica foi aplicada em uma escola pública no interior do Estado do Rio de Janeiro e objetivou visibilizar as experiências sociais desenvolvidas junto aos estudantes de uma escola pública da rede municipal de ensino de Volta Redonda-RJ. O escopo metodológico se desenvolveu por meio dos Estudos do Cotidiano, tendo a roda de conversa como sua principal dinâmica (instrumento) para apreensão do percurso dos(as) sujeitos praticantes em sua trajetória de aprendizagemensino. A sequência didática se desenvolveu por intermédio de seis aulas, possibilitando a aquisição dos seguintes resultados: a) promoção de um espaço de dialogicidade e conflito epistemológico entre os(as) estudantes; b) a roda de conversa propiciou a horizontalização dos conhecimentos trazidos ao chão da escola, perpassando pelos artigos teóricos propostos, os vídeos, as imagens retiradas das redes sociais, as imagens utilizadas pelos(as) estudantes e suas experiências individuais e coletivas; c) a referida prática educativa permitiu a construção de conhecimentos em redes de subjetividade, promovendo a ruptura com a hierarquização de conhecimentos e valorizando a diversidade de olhares e modos de compreensão do/sobre/com o mundo.
\end{abstract}

Palavras-chave: Currículo; Educação de Jovens e Adultos; Saúde.

Abstract: The present study has its genesis in a professional master's dissertation in the fields of health and environment and characterizes a didactic proposal to the health discussion in Youth and Adult Education (EJA). This pedagogical proposition was applied in a public school in the countryside of Rio 
de Janeiro and aimed to make visible the social experiences developed with the students of a public school from the municipal education system of Volta Redonda - RJ. The methodological scope was developed through Daily Studies, with talking circles as its main dynamic (instrument) to the comprehension of the subjects'paths in their learning / teaching trajectory. The didactic sequence was developed utilizing six classes, making it possible the acquisition of the following results: a) promotion of a dialogical space and epistemological conflict among the students; b) the talking circle propitiated the horizontalization of the knowledge brought to the school; going through the theoretical articles suggested, the videos, the images taken from the social network, the pictures used by the students, the individual and collective experiences of the students; $c$ ) The educative practice allowed the construction of knowledge in subjective networks, promoting the rupture with the Knowledge hierarchization and valuing the diversity of perspectives and ways of comprehension of the world.

Keywords: Curriculum; Youth and Adult Education; Health.

Resumen: El presente trabajo tiene su origen en una disertación de maestría profesional en el área de la salud y el medio ambiente y se caracteriza como una proposición didáctica para la discusión de la salud junto con Educación de Jóvenes y Adultos (EJA). La referida proposición pedagógica se aplicó en una escuela pública en el interior del estado de Río de Janeiro y tuvo como objetivo hacer visibles las experiencias sociales desarrolladas con estudiantes de una escuela pública de la red municipal de enseñanza de Volta Redonda-RJ. El alcance metodológico se desarrolló a través de los Estudios del cotidiano, teniendo la rueda de conversación como su principal dinámica (instrumento) para la aprehensión del recorrido por los sujetos practicantes en sus trayectorias de enseñanza-aprendizaje. La secuencia didáctica se desarrolló a través de seis clases, habilitando la adquisición de los siguientes resultados: a) promoción de un espacio de dialogicidad y conflicto epistemológico entre estudiantes; b) La rueda de conversación proporcionó la horizontalización de los conocimientos traídos al piso de la escuela; repasando los artículos teóricos propuestos, los videos, las imágenes tomadas de las redes sociales, las imágenes utilizadas por los(las) estudiantes, las experiencias individuales y colectivas de los estudiantes; c) La referida práctica educativa permitió la construcción del conocimiento en redes de subjetividad, promoviendo la ruptura con la jerarquizacion del conocimiento y valorando la diversidad de miradas y formas de entender del / sobre / con el mundo.

Palabras claves: Curriculum; Educación de Jóvenes y Adultos; Salud.

\section{Introdução}

Em meio à militância na docência da Educação Física na Educação de Jovens e Adultos, especificamente no interior do Estado do Rio de Janeiro, nos deparamos, desde 2007 - Decreto presidencial n ${ }^{\circ}$. 6.286/2007-, com uma política intersetorial (Programa Saúde na Escola - PSE) que intenciona fortalecer as ações "na perspectiva do desenvolvimento integral e proporcionar à comunidade escolar a participação em programas e projetos que articulem saúde e educação, para o enfrentamento das vulnerabilidades [...]” (BRASIL, 2011, p. 6).

Porém, ao adentrarmos em uma investigação mais ampla na tentativa de pesquisar o modus operandi do PSE, particularmente no município de Volta Redonda, nos deparamos com uma prática que apresentava contradições para um programa que se pretende intersetorial, como 
por exemplo: ausência de ações integradas entre os(as) gestores(as) e os(as) respectivos(as) profissionais envolvidos(as), burocratização dos serviços, concepção de saúde reduzida à razão biomédica proporcionando uma hierarquização nas ações. Para Silva Júnior (2014, p. 799) “o programa é prescrito pelo setor de saúde para ser executado pelo setor de educação, ocorrendo desta forma uma visão setorial do programa intersetorial".

Nessa perspectiva, Souza, Esperidião e Medina (2017, p. 1786), ao analisarem a ação intersetorial e o processo de implementação do PSE em um município de região metropolitana do Nordeste brasileiro, consideraram que apesar dos participantes entenderem a intersetorialidade como ação compartilhada, não tematizavam e não discutiam coletivamente o "compartilhamento de poder, o diálogo, as decisões horizontais e as ações integradas como dimensões da prática intersetorial", favorecendo o surgimento de práticas setorizadas e hierarquizadas, o que compromete as decisões coletivas e a efetividade das ações.

Para Cargnin (2015), o PSE é uma estratégia biopolítica de gestão da vida dos educandos, visto que se relaciona com as condições de saúde, de prevenção de doenças e promoção da saúde. A autora, ao pesquisar o referido programa, considerou ser essa uma política de governamento de modo a estabelecer um processo normalizador. Tal constatação parte do pressuposto de que há no programa uma estratégia que estabelece determinados comportamentos em que o indivíduo deve assumir, na forma de condutas em sua vida, competências a fim de tornar-se um multiplicador na família e na comunidade.

Considerando ser a saúde uma temática relevante a ser problematizada no cotidiano escolar e, portanto, um conhecimento que deve compor o currículo dos(as) estudantes, nos aproximamos da noção de currículo como criação cotidiana (OLIVEIRA, 2012), no intuito de produzirmos coletivamente uma proposta de sequência pedagógica. Aprendemos com Freire (2011) que os processos de aprendizagemensino ${ }^{1}$ precisam ser significados a partir da realidade em que são experienciados, assim, opondo-se ao modelo proposto pelo PSE, em que as doze ações propostas são apresentadas como único caminho a ser percorrido pelas escolas pactuadas.

Cabe frisar que a pesquisa que originou a presente proposta pedagógica se aproximou das Sociologias das Ausências e das Emergências, porque se por um lado disponibiliza as experiências de reconhecimento ${ }^{2}$ construídas no chão de uma escola pública, por outro lado,

\footnotetext{
${ }^{1}$ A opção pela junção de palavras se deve pela tentativa de superar a dicotomização herdada da ciência moderna. "Nesse texto aparecerão outros termos assim unidos: ensino e aprendizagem ou ensinar e aprender que, além de tudo, são invertidos e aparecem como aprenderensinar, já que ninguém ensina se não aprendeu antes" (ALVES, 2003, p. 66).

${ }^{2}$ Consideramos que as experiências de reconhecimento são aquelas que emergem de diálogos e conflitos possíveis entre sistemas de classificação social: "Nas margens ou nos subterrâneos dos sistemas dominantes - exploração, natureza capitalista, racismo, sexismo, e xenofobia [...]” (SANTOS, 2010, p. 122).
} 
contribui para o estímulo na construção de outros saberes, por intermédio da criação de experiências futuras, concretas e possíveis (SANTOS, 2010).

Outrossim, torna-se relevante ainda mencionar que as sociologias supramencionadas são oriundas da razão cosmopolita, uma racionalidade que opera excedendo a compreensão ocidental de mundo (SANTOS, 2010). Isto é, romper com a razão moderna, pois ela reduz seu modo de percepção a uma ótica monocultural, que, no caso deste estudo, emerge na forma da concepção de saúde centrada apenas no aspecto anátomo-biológico.

No que diz respeito à discussão desenvolvida na proposta pedagógica, torna-se relevante ressaltar que buscamos problematizar a noção de saúde, nos aproximando das ideias de Boaventura de Souza Santos (2010) por duas questões complementares: primeiro, pela intenção de contrapor-nos à tentativa de padronização curricular contida na proposta pelo PSE; segundo, pela contraposição à corrente que opera via o binômio saúde/doença, reduzindo a saúde à mera prática de exercício físico e /ou atividade física (via saber biomédico): o "corpo é visto de forma fragmentada e destituído de subjetividades, que podem ser percebidos tanto nos âmbitos da formação e da pesquisa como no da intervenção" (FERNANDES DE FREITAS; CARVALHO; MONTEIRO MENDES, 2013, p. 644).

Assim, considerando a necessidade de problematizar a noção de saúde, o estudo objetivou visibilizar o modo como os(as) estudantes pensam a saúde, estabelecendo um diálogo a partir das questões singulares que se apresentam na interface entre a escola e a comunidade. Considerando ser este estudo uma pesquisa de campo, salientamos que o mesmo foi submetido ao comitê de ética de pesquisa do Centro Universitário de Volta Redonda, sendo aprovado sob o registro CAAE: 79105117.0.0000.5237.

\section{Metodologia}

\subsection{Sujeitos da pesquisa}

A investigação foi desenvolvida com estudantes da EJA, oriundos de uma escola da rede pública municipal de Volta Redonda, interior do estado do Rio de Janeiro, que atende a treze comunidades do município, especificamente com uma turma de 34 estudantes com faixa etária compreendida entre quinze e dezessete anos, contendo adolescentes que já atuavam no mercado de trabalho e, em sua grande maioria, de classe social baixa e afrodescendentes. A referida turma foi composta por doze estudantes do gênero feminino e vinte e dois estudantes do gênero masculino. Dentre as meninas, uma adolescente não concluiu o ano letivo, pois engravidou e, 
após o segundo semestre, não conseguiu frequentar a escola. Havia também uma adolescente com Síndrome de Down. Dentre os estudantes, um deles ficou ausente durante todo o ano letivo, uma vez que esteve preso em um centro de detenção devido ao seu envolvimento com o tráfico de drogas.

\subsection{Pressupostos metodológicos}

No que diz respeito ao escopo metodológico, consideramos fundamental para a presente proposta a perspectiva de Benjamin (1994, p. 37) em relação à narrativa: a arte de narrar é um acontecimento infinito, "pois um acontecimento vivido é finito, ou pelo menos encerrado na esfera do vivido, ao passo que o acontecimento lembrado [narrado] é sem limites, porque é apenas uma chave para tudo o que veio antes e depois".

Considerar tal perspectiva se deve em razão da ruptura com o modelo proposto pela ciência moderna que hierarquiza saberes ao estabelecer uma relação de sujeito/objeto ao modo pesquisador/entrevistado, em que a entrevista ou o questionário emerge à maneira inquisitória. Ao contrário, ao nos aproximarmos dos estudos do cotidiano buscamos na roda de conversa (FREIRE, 2011; OLIVEIRA; REIS, 2017) - instrumento da pesquisa - um espaço de troca e diálogo. No caso do presente estudo, por se tratar da EJA, buscamos na dialogicidade freireana a metodologia para a produção de dados, pois entendemos que a partilha de experiências permite acessar "a inscrição de toda história e de toda memória individuais em uma história e memórias coletivas" (POLLAK, 2010, p. 12).

A dialogicidade proposta neste estudo é concebida a partir da lógica freireana, visto que considera como elemento principal a participação dos(as) estudantes no processo educativo e, portanto, como sujeito que produz conhecimentos (FREIRE, 2011). Desse modo, o processo de aprendizagemensino não é uma mão de via única, não é direcionado exclusivamente pelo professor, mas um processo realizado em diálogo com os(as) estudantes.

Assim, as rodas de conversa emergem no estudo como uma metodologia que valoriza a experiência, visto que permite a "junção entre a teoria e a prática, na conexão entre ideias, pensamentos e vida" (MENDES; PÉREZ, 2017, p. 176). Dito de outra forma, valorizamos o fluxo de conversações para a produção dos dados da pesquisa. A intenção foi utilizar as redes de conversações (imagens, textos, diálogos) para acessar as narrativas relacionadas à temática da saúde. Considerando a necessidade de apreender as impressões dos estudantes nos momentos de dialogicidade, utilizamos para a captação do áudio um microfone de lapela acoplado a um notebook Inspiron 15-série 5000. 


\section{Pressupostos Políticos-Epistemológicos: por uma construção de conhecimento em rede}

A presente proposta didático-pedagógica teve como intenção extrapolar a noção de currículo que emerge da ótica tradicional, classificatória e hierarquizante que, ao se pensar única e exclusiva, toca o chão da escola de maneira descontextualizada da realidade social e dos determinantes históricos e sociais que interferem nesse espaço/tempo, atuando de modo excludente. De outro modo, Oliveira (2012) trabalha com a ideia de que o currículo se desenvolva a partir da tessitura ${ }^{3}$ de conhecimentos em rede, visto que se configura no enfrentamento ao paradigma arbóreo que opera a partir da perspectiva linear, priorizando o "sequenciamento obrigatório, do mais simples ao mais complexo, dos saberes aos quais se devem ter acesso (OLIVEIRA, 2007, p. 87). Contrariamente, o currículo como criação cotidiana trabalha com a ideia de que os conhecimentos são tecidos em realidades complexas por estudantes oriundos de diversas escolas e, por isso, ressignificam singularmente as informações que chegam até eles (OLIVEIRA, 2012). Tal noção, ao contrário do que estabelecem as teorias modernas, trabalha com a ideia de que os conteúdos, aos quais são submetidos os(as) estudantes, se transformam em conhecimentos apenas quando ressignificados, entretanto, para que esse processo ocorra necessitam articular-se às questões sociais, políticas, culturais que determinam e impactam as vidas das pessoas, pois passam a adquirir um sentido particular, que pode não ser exclusivamente o mesmo que o transmissor da informação pressupôs (OLIVEIRA, 2012).

De outro modo, é importante que se compreenda que não é pelo fato de ouvir uma informação que haverá aprendizagem, pois esse processo somente se efetivará caso o que tenha sido dito se articule aos interesses, crenças, valores ou saberes da pessoa interessada. Isso significa que não há um único caminho ou um caminho estabelecido a priori de como aprender, pois, se cada ser humano possui uma corporeidade que se constrói a partir do seu processo sincrônico no mundo, cada sujeito se configura por experiências próprias que o singularizam, não podendo haver um padrão ou modelo matricial, como nos propõe o paradigma arbóreo e diversas teorias de aprendizagem (LIBÂNEO, 2005).

\footnotetext{
${ }^{3} \mathrm{O}$ termo tessitura foi buscado na música permitindo compreender o modo como se relacionam as notas para compor uma peça (ALVES, 2003). Assim, no presente estudo, a tessitura de conhecimentos em redes é entendida como sendo o modo como ressignificamos os produtos que nos chegam concedendo um sentido particular, pois articulamos tal consumo às nossas redes de subjetividades e determinantes de raça, classe social, gênero, dentre outros.
} 
Assim, considerando que o processo de aprendizagemensino ${ }^{4}$ ocorre de modo singular, porque se conecta às experiências individuais e coletivas e aos saberes anteriores dos(as) estudantes, as possibilidades de conexões para novas aprendizagens são plurais, não fazendo "sentido pressupor um trajeto único e obrigatório para todos os sujeitos em seus processos de aprendizagem" (Idem, p. 87).

Outrossim, Certeau (1994) também nos auxilia a compreender que os sujeitos ordinários - o sujeito comum - não se posicionam alienadamente diante das produções que chegam até eles, mas agem astutamente, de modo disperso quase invisível, produzindo e disseminando criações anônimas, reinventadas a partir de seus anseios, desejos e necessidades.

Nessa lógica, a racionalidade moderna ocidental, caracterizada pelo conhecimento científico eurocêntrico, é um pensamento que age abissalmente, pois consiste na fabricação de um sistema que divide a realidade por intermédio de uma linha que separa as distinções visíveis e invisíveis (SANTOS, 2010). Para o autor, a monocultura do saber ou do rigor do saber é o modo mais poderoso de não existência, pois ao ser transformado ao longo da modernidade, pelo imaginário colonial - eurocêntrico -, como único conhecimento válido, transfigurou-se em uma totalidade que desconsidera as outras formas alternativas de saber em cultura, religião, folclore, dentre outros.

Especificamente, a escola, ao desenvolver suas ações educativas, tendo a ótica moderna como referência do processo de aprendizagemensino, desqualifica os conhecimentos e as experiências trazidas pelos(as) estudantes, pois entende que os(as) docentes são os únicos a possuírem conhecimentos válidos socialmente.

Nesta linha de pensamento, no intuito de superar a produção da não existência, buscamos a proposição de Santos (2018), visto que a Sociologia das Ausências procura o enfrentamento da monocultura do saber, por intermédio da Ecologia dos Saberes, uma condição para o estabelecimento do enfrentamento ao paradigma moderno, pois enquanto não houver justiça cognitiva, credibilização de saberes alternativos e tradicionais, não haverá justiça social.

\subsection{Sequência didática}

Considerando os pressupostos político-epistemológicos apresentados, a sequência didático-pedagógica desenvolvida foi a seguinte: inicialmente, uma pesquisa

\footnotetext{
${ }^{4}$ A opção por trabalhar com a junção em torno dos processos de aprendizagemensino se deve pela aproximação à discussão de Oliveira (2013), pois são redes nas quais estão presentes as escolhas, os desejos e as possibilidades políticaspráticasexpressivas dos sujeitos neles envolvidos devendo o ensino enredar-se às especificidades locais e naquilo que efetivamente se faz.
} 
socioantropológica (FREIRE, 2011), no intuito de compreender as questões e os determinantes que atuam interferindo ou influenciando no modo como entendem a temática da saúde. A roda de conversa, por seu caráter informal, permitiu que as questões sociais, políticas, econômicas, culturais, presentes nas redes cotidianas dos(as) estudantes aparecessem nos diálogos estabelecidos durante o referido procedimento metodológico.

No segundo momento, houve um confronto acerca do conceito de saúde produzido pelos(as) discentes na primeira aula, uma aproximação da hermenêutica diatópica. Recordando Santos (2018), hermenêutica diatópica “consiste no trabalho de interpretação entre duas ou mais culturas com vista a identificar preocupações isomórficas entre elas e as diferentes respostas que fornecem para elas" (SANTOS, 2018, p. 271).

No terceiro momento, apresentamos o relato de caso de uma diarista contendo suas condições de descanso, transporte e trabalho. Durante essa intervenção, utilizamos a roda de conversa no intuito de ampliar o diálogo e o compartilhamento de ideias sobre estilo de vida. Ao final da aula, deixamos com os(as) estudantes algumas perguntas para serem respondidas e apresentadas na aula posterior.

No quarto momento, os(as) estudantes apresentaram as respostas às perguntas realizadas na aula anterior. Posteriormente, retomamos a roda de conversa no intuito de problematizar as questões polêmicas oriundas das respectivas respostas.

No quinto momento, foram apresentados os vídeos "Outro olhar - Dia Nacional de Combate ao Sedentarismo" e "Sedentarismo: não exercitar-se é um passo para adquirir doenças como obesidade e diabetes", o que nos permitiu problematizar a noção de sedentarismo, por intermédio de debates e reflexão sobre tal temática na roda de conversa.

No sexto momento, os(as) estudantes realizaram um trabalho coletivo tendo a temática da saúde como centralidade. Cabe frisar que o processo avaliativo utilizou imagens, no intuito de priorizar outras formas de leitura do mundo.

Quadro 1. Resumo das aulas

\begin{tabular}{|l|l|l|}
\hline Aulas & \multicolumn{1}{|c|}{ Objetivos } & \multicolumn{1}{|c|}{ Estratégia } \\
\hline Aula1 & $\begin{array}{l}\text { - Investigar a concepção de saúde dos(as) } \\
\text { estudantes. }\end{array}$ & $\begin{array}{l}\text { Aula Expositiva e Rodas de } \\
\text { conversa em sala de aula; }\end{array}$ \\
\hline Aula 2 & $\begin{array}{l}\text { - Confrontar as supostas falas (da aula anterior) } \\
\text { com outras realidades por intermédio do uso de } \\
\text { imagens. }\end{array}$ & $\begin{array}{l}\text { Aula Expositiva com o uso do } \\
\text { Power Point (exibição das imagens) } \\
\text { e Roda de conversa; }\end{array}$ \\
\hline Aula 3 & $\begin{array}{l}\text { - Apresentar os relatos (experiências sociais de um } \\
\text { trabalhador e de estudantes da turma), discutindo o } \\
\text { estilo de vida e a relação com o sedentarismo. }\end{array}$ & Rodas de conversa e questionário; \\
\hline Aula 4 & $\begin{array}{l}\text { - Discutir os resultados do questionário, } \\
\text { contextualizando as respostas dos(as) estudantes, a a }\end{array}$ & Roda de conversa; \\
\hline
\end{tabular}




\begin{tabular}{|c|c|c|}
\hline & $\begin{array}{l}\text { partir das noções apresentadas nas aulas } \\
\text { anteriores. }\end{array}$ & \\
\hline Aula 5 & $\begin{array}{l}\text { - Apresentar um vídeo sobre sedentarismo, } \\
\text { problematizando a partir dos depoimentos e } \\
\text { experiências (práticas corporais) dos(as) } \\
\text { estudantes da turma. }\end{array}$ & $\begin{array}{l}\text { Aula Expositiva com o uso de } \\
\text { vídeos e Roda de conversa; }\end{array}$ \\
\hline Aula 6 & $\begin{array}{l}\text { - Confeccionar um trabalho em formato de cartaz, } \\
\text { utilizando imagens, sobre a temática saúde. }\end{array}$ & $\begin{array}{l}\text { Atividade em grupo com confecção } \\
\text { de cartazes com frases e imagens. }\end{array}$ \\
\hline
\end{tabular}

Fonte: Autoria Própria.

\section{Relato da Experiência: À guisa de resultados}

Neste momento, vamos nos deter na apresentação da proposta de sequência pedagógica desenvolvida no cotidiano de uma escola pública da rede municipal de Volta Redonda tendo a temática da saúde como centralidade.

Um aspecto relevante a ser ressaltado é que as aulas da EJA no município de Volta Redonda são conduzidas enredadas à pedagogia de projetos, cuja temática para a execução do projeto anual ocorre em uma avaliação diagnóstica realizada com os(as) estudantes no início do ano letivo. Considerando que as escolas, singularmente, constroem a temática do seu projeto, na ocasião do desenvolvimento deste estudo - em 2018 -, a temática do projeto da escola pesquisada foi "Meu Corpo, Minha Identidade", com o objetivo de desenvolver o autoconhecimento, fortalecendo e ampliando o conceito de identidade dos(as) estudantes.

Conforme apresentado no Quadro 1, a primeira aula teve como objetivo investigar o conceito de saúde a partir da percepção dos(as) estudantes da EJA. Estabelecemos uma aproximação realizando uma pesquisa sob a ótica freireana (socioantropológica), no intuito de localizar as palavras geradoras (FREIRE, 2011). No caso deste estudo, tal procedimento foi realizado por meio de quatro perguntas, conforme disposto a seguir: 1. O que é saúde? 2. Qual é o modelo de saúde que temos? 3. Qual é a saúde que queremos? 4. Como chegar lá? Cabe salientar que as respostas dos(as) estudantes foram utilizadas no transcorrer da sequência pedagógica a ser apresentada nesta pesquisa.

Na intenção de metodologicamente apresentar os dados produzidos e, simultaneamente, resguardar a identidade dos(as) participantes da pesquisa, optamos por utilizar a primeira letra dos nomes dos(as) estudantes.

No que se refere ao instrumento utilizado para a obtenção das respostas, a roda de conversa (OLIVEIRA, 2012) foi escolhida por entendermos que esta metodologia permite o diálogo e o compartilhamento de ideias e a apreensão das narrativas dos(as) participantes do estudo: 
[...] a arte de narrar é um acontecimento infinito, pois um acontecimento vivido é finito, ou pelo menos encerrado na esfera do vivido, ao passo que o acontecimento lembrado [narrado] é sem limites, porque é apenas uma chave para tudo o que veio antes e depois (BENJAMIN, 1994, p. 37).

Partindo da ótica supramencionada, o que buscamos evidenciar é a relação da experiência como memória coletiva, visto que se constrói no emaranhado dos condicionantes econômicos, culturais, sociais, políticos, de gênero, de raça, dentre outros. Nesse sentido, a pergunta inicial feita à turma - O que é saúde? - nos propiciou as seguintes narrativas:

R: Ah...tomar banho, escovar dente, passar desodorante...

D: Se relacionar, ir à igreja...

J: Viver.

T: Ter trabalho.

J.V: Boa alimentação, dormir bem...

M: Correr...

T: Beber água, fazer exercícios, alimentação, evitar doenças...

E: Evitar doenças...

T: Dormir bem...

G: Se prevenir, cuidar da alimentação...

A: Tomar vacina.

E: Praticar esporte é saudável, ir à academia.

R: Fazer exercícios...

F: Praticar exercícios físicos

J.B: Higiene corporal.

P: Ir ao médico, fazer prevenção...

Cabe frisar que, nesse primeiro momento, a pesquisa teve como objetivo o levantamento das situações-limites, ou seja, a investigação da percepção que os(as) estudantes possuem em um "dado momento histórico, como uma barreira, "como algo que eles não podem ultrapassar" (FREIRE, 1987, p. 51). Isto é, aspectos que "implicam a existência daqueles a quem diretamente ou indiretamente servem e daqueles a quem negam e freiam" (FREIRE, 2011, p. 94), nos serviram para planejar as ações de intervenção educativa.

Assim, considerando que as falas dos(as) estudantes revelam um universo temático (FREIRE, 2011), vamos entender que elas revelam o nível de percepção da realidade do(a) estudante, sua visão de mundo. Portanto, percebemos que quase todas as narrativas supramencionadas buscam a perspectiva organicista ou anátomo-biológica como referência de saúde.

Parece-nos que essa predominância não se dá ao acaso, pois Palma et al. (2010), ao investigarem a revista "Boa Forma", no intuito de identificarem o apelo mercadológico do discurso de saúde emitido pela referida revista, afirmam que na "literatura científica biomédica ou em suas construções contemporâneas que ecoam na mídia, é possível encontrar uma extensa variedade de discursos advogando a relação entre corpos em forma e a ideia de evitar riscos à 
saúde" (PALMA et al., 2010, p. 32). Tal ideia parece corroborar o pensamento que opera concebendo a saúde a partir de pressupostos biomédicos, utilizados para padronizar e hierarquizar os corpos. Além disso, como se trata de uma turma da aula de educação física, pensamos que a questão do exercício, esporte, academia pode ter sido enviesada por isso.

Prosseguindo com o desenvolvimento da sequência pedagógica, na segunda aula, cujo objetivo foi confrontar as falas dos(as) estudantes obtidas na aula anterior com outras situações do cotidiano, optamos por diferenciar atividade física e exercício físico, visto que tais definições já haviam sido trabalhadas no primeiro bimestre e foram apontadas pelos(as) estudantes como fatores importantes para se ter saúde. É importante salientar que a sinalização por parte dos(as) estudantes quanto à importância do exercício e da atividade física para a aquisição de saúde se revela como indício da concepção biomédica já anunciada anteriormente.

No intuito de problematizar as falas geradoras (FREIRE, 2011) obtidas na primeira aula, optamos por uma aula expositiva com o uso do Power Point, em que apresentamos imagens que nos permitiram questionar e, simultaneamente, descodificar o mundo vivido: “[...] problematizando-o, descodificando-o criticamente, no mesmo movimento da consciência o homem se redescobre como sujeito instaurador desse mundo de sua experiência” (Idem, p. 15).

Assim, apresentamos as imagens e estabelecemos um movimento de dialogicidade entre professor/estudantes e entre estudantes/estudantes, na perspectiva de cocriação, um conhecimento híbrido, que se constrói singularmente, na ótica do currículo como construção cotidiana5 (OLIVEIRA, 2012).

Portanto, a partir da imagem (Figura 1), realizamos alguns questionamentos, como por exemplo: A pessoa na imagem está realizando uma atividade física ou um exercício físico?

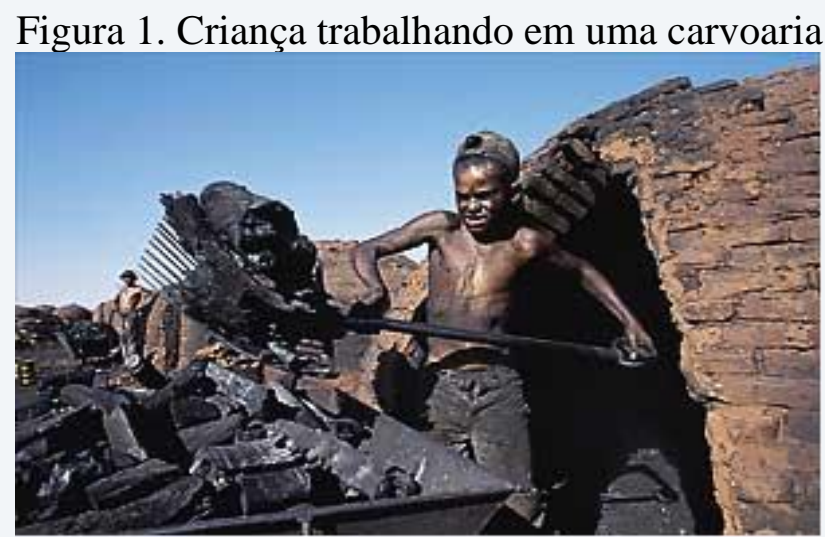

Fonte: Página "Sarau Para Todos” (10/04/2014)6.

\footnotetext{
${ }^{5}$ Neste estudo, o currículo é entendido como sendo uma produção singular dos sujeitospraticantes do cotidiano nos abrindo possibilidades de ir além da compreensão universalizante, pois se constrói a partir dos processos de aprendizagemensino, cotidianos nas/das/com as escolas em seus contextos particulares (OLIVEIRA, 2012).

${ }^{6}$ Disponível em: https://sarauparatodos.wordpress.com/2014/10/10/capitalismo-e-criancas/.
} 
Ao apresentarmos a imagem de uma criança na carvoaria, os(as) estudantes responderam que ela realizava atividade física, pois estavam partindo da noção de que a atividade física é toda ação não sistematizada que gera gasto calórico e, de modo distinto, exercício físico emerge de uma ação sistemática (CHEIK et al., 2008). Desse modo, retornávamos à pergunta da primeira aula no intuito de problematizar e descodificar o modo como percebem a realidade: mas, a criança da imagem possui saúde?

As narrativas que emergiram do diálogo foram variadas nos permitindo problematizar novamente com os(as) estudantes:

Aluno F: Não dá pra saber professora...

Aluna E: Não tem saúde porque faz as coisas em excesso pra idade.

Aluno G: Não tem saúde porque trabalha no sol, não se alimenta direito.

Aluno JV: Como você sabe que ele não se alimenta direito?

Para Freire (2011, p. 16), “o diálogo fenomeniza e historiciza a essencial intersubjetividade humana; ele é relacional e, nele, ninguém tem iniciativa absoluta. Os dialogantes 'admiram' um mesmo mundo”. Trazer a perspectiva dialógica (FREIRE, 2011) como uma metodologia de ensino favoreceu o processo de construção de saberes, pois entendemos que a tessitura de conhecimentos ocorre a partir de uma dinâmica de enredamento.

Para Oliveira (2012), tal processo ocorre a partir do intercâmbio de experiências e de saberes coletivos, permitindo aos participantes ressignificar conhecimentos, portanto, fazíamos novas indagações na intenção de promover o debate e a construção de outros saberes, por exemplo: anteriormente vocês não disseram que ter saúde é fazer atividade física? Os novos questionamentos que surgiam, por meio do diálogo, permitiam aos estudantes refletir sobre o modo como percebem o mundo, pois realizávamos o conflito entre as narrativas: “A intersubjetividade, em que as consciências se enfrentam, dialetizam-se, é a tessitura última do processo histórico de humanização. [...] A consciência emerge do mundo vivido, objetiva-o, problematiza-o, compreende-o como projeto humano" (FREIRE, 2011, p. 17).

Assim, durante o processo de debate acerca das imagens, buscávamos realizar um movimento que, de certo modo, se aproxima das ecologias de saberes (SANTOS, 2018), porque se coloca contrário às metodologias qualitativas que buscam extrair conhecimentos dos sujeitos desvinculados das lutas sociais, visto que procurávamos o reconhecimento dos saberes dos sujeitos investigados, no intuito de romper com a lógica colonial "que nega a própria condição ontológica dos sujeitos excluídos enquanto portadores e produtores de saberes" (FASANELLO; NUNES; PORTO, 2018, p. 401). 
Posteriormente, passamos a outro momento significativo da aula, pois apresentamos imagens de alguns artistas que possuem o corpo considerado esteticamente perfeito (novamente), a partir dos pressupostos estabelecidos pela mídia (Figura 2).

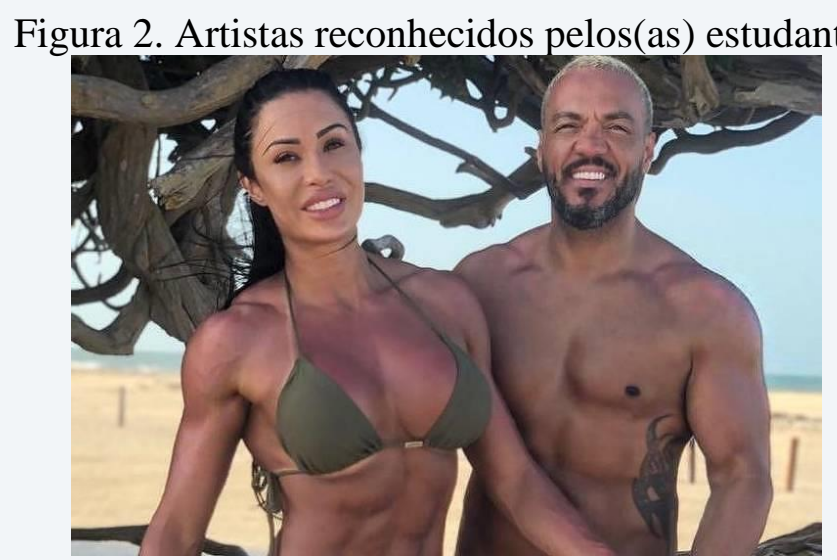

Fonte: Folha de São Paulo (11/10/2019)7.

Gostaria de retomar aqui a ideia de Freire (2011) e do sociólogo Charles Wright Mills (1975), de modo específico à proposição de uma imaginação intelectual entrelaçada à noção da investigação como um ofício, em que o pesquisador é concebido como um artesão (SANTOS, 2018).

Pensar a partir dessa lógica nos moveu a uma investigação temática e, em decorrência, ao trabalho co-labor-ativo com os sujeitospraticantes do estudo, pois não realizamos uma ação investigativa na direção da pesquisa qualitativa extrativista - aquela que se apropria do saber do outro desconsiderando seu lugar de produtor de conhecimento -, mas construindo junto, coletivamente: "Pensar que não se dá fora dos homens, nem num homem só, nem no vazio, mas nos homens e entre os homens, e sempre referido à realidade" (FREIRE, 2011, p. 101). As narrativas a seguir nos permitem acessar as percepções dos(as) estudantes:

Aluno J: Ah, ela tem saúde porque tem acompanhamento médico e tal... Aluno R: Ah, mas ela usa bomba, não come, faz dieta...

Aluna A: Ela tem silicone...

Assim, fundado no fazer sociológico explicitado, buscamos promover novamente o diálogo entre professor/estudante e estudante/estudante: Essas pessoas possuem saúde? Por quê? O que eles(as) fazem para conseguir esse corpo? O exercício físico é sinônimo de saúde?

\footnotetext{
${ }^{7}$ Disponível em: https://f5.folha.uol.com.br/celebridades/2019/10/belo-relembra-prisao-por-trafico-de-drogas-doceu-ao-inferno.shtml.
} 
Assim, considerando a discussão de Rago (2006), discutimos com os(as) estudantes o comportamento civilizatório da sociedade contemporânea que credibiliza a crescente cultura do narcisismo e que envolve as práticas corporais de embelezamento difundidas pela mídia, instaurando valores individualistas e padrões corporais (Figura 2).

Desse modo, passamos a questionar a relação entre exercício físico, atividade física e sedentarismo, visto que a prevalência do sedentarismo ou da inatividade física, em determinadas populações, tem sido apresentada à população como sendo a responsável pela ocorrência de diferentes doenças. Os autores ainda ressaltam que a ausência de "clareza sobre o significado do que seja sedentarismo ou mesmo inatividade física" contribui significativamente para o estabelecimento da normalização dos corpos e, portanto, reduz a noção de saúde ao viés biomédico e ao binômio saúde/doença (PALMA; VILAÇA, 2010, p. 106).

Outra imagem utilizada nesse momento da aula, no intuito de problematizar o padrão estético como sinônimo de saúde, foi a imagem da cantora Jojo Todynho (Figura 3). Simultaneamente à exposição da imagem, realizamos outro questionamento: Qual a diferença entre os corpos apresentados?

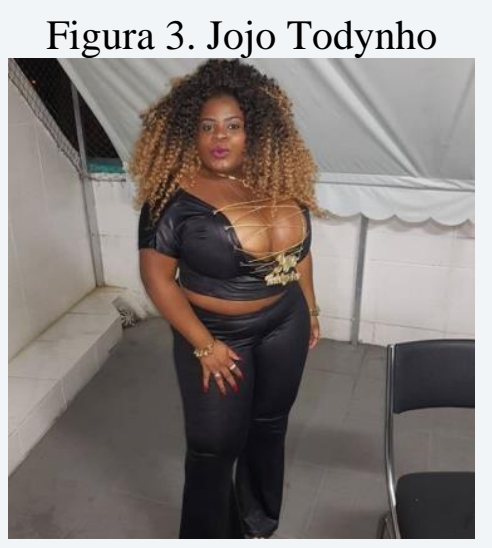

Fonte: Twitter8.

De imediato, as narrativas dos(as) estudantes revelaram que o corpo da Jojo Todynho "era natural" (estudante - J.V.) e, para se igualar à Graciane Barbosa, no intuito de obter o padrão corporal, deveria, dentre outras coisas, realizar os seguintes procedimentos:

P: Comer pouco.

A: Tomar muito suplemento, bomba.

J. V: Comer ovo o dia todo [...]. Ela tem um objetivo.

P. O: Batata doce [...]. É igual a um corpo de gogo boy.

\footnotetext{
${ }^{8}$ Disponível em: https://twitter.com/JojoMarontinni/status/922270277400133632
} 
No intuito de refletir com os(as) estudantes a contradição entre as figuras das duas artistas supramencionadas, trouxemos a noção de "Bem Viver" (MENESES, 2005; MARTINS, 2016) para contrapor o ideal de beleza e saúde preconizado pela indústria cultural. Meneses (2005), ao desenvolver uma pesquisa no intuito de conhecer a noção de saúde na população da cidade de Maputo, em Moçambique, nos revela que a saúde para essa população se constitui por intermédio de outros pressupostos como acesso à escola, alimentação, roupas, possibilidade de cuidados com a higiene, saneamento, dentre outros. Já Martins (2016) centra a sua discussão de Bem Viver nas comunidades tradicionais da América do Sul e na cosmovisão desses povos que perpassa por uma perspectiva de coletividade que propõe formas alternativas de vida social e de economia, respeitando a relação que se constrói com o outro e com o meio ambiente. Portanto, tais perspectivas nos possibilitaram a discussão da noção de saúde fundada em outros pressupostos, indo além do reducionismo biológico característico do pensamento colonizador moderno: "Vivir Bien entre nosotros, es una convivencia comunitaria con interculturalidad y sin asimetrías de poder, no se puede Vivir Bien si los demás viven mal” (MOLLO, 2011, p. 30$31)$.

Na esteira dessa discussão, na terceira aula, apresentamos para a turma o relato de caso, a partir da pesquisa de Mourão (1999), em que uma mulher casada, diarista, mãe de cinco filhos e moradora da comunidade de Queimados, município do estado do Rio de Janeiro, obtinha uma qualidade de vida e de saúde determinadas pela sua condição de classe, gênero, raça e em consequência à sua condição de descanso, transporte e trabalho influenciadas por tais condicionantes.

Posteriormente à leitura do material, utilizamos a roda de conversa no intuito de ampliar o diálogo e o compartilhamento de ideias discutindo o estilo de vida das pessoas que passam pelas mesmas situações em seu cotidiano. O debate ainda propiciou a problematização sobre o tempo disponível e a motivação das pessoas para a realização de exercício físico, visto que, no transcorrer do dia, há um dispêndio significativo de calorias para realizarem o tipo de trabalho descrito no relato e, portanto, no cumprimento de suas atividades laborais.

Em contrapartida, ainda foi possível abordar a temática referente à condição financeira da população brasileira para se alimentar adequadamente e ainda pagar o tipo de exercício físico preconizado pela mídia: academias de ginástica e musculação. Nesse momento, trouxemos os conhecimentos oriundos do estudo de Waissmann (2003), intitulado Desigualdade Social e Atividade Física. Para Waissmann (2003), são diversos os determinantes sociais que interferem e condicionam as possibilidades das pessoas para realizarem a atividade física, por exemplo: a 
classe social, especificamente o aspecto econômico, determina o nível de escolaridade, o acesso ao trabalho e, em decorrência, a renda que, por consequência, afeta a longevidade das pessoas. Porém, outros aspectos permanecem encobertos na sociedade brasileira devido ao poder heteropatriarcal, que segue colonizando e excluindo seres humanos do acesso a melhores condições de vida: a condição de classe, de raça e de gênero.

Nesse sentido, recordamos o pensamento de Mbembe (2016, p. 128) que, ao discutir o estabelecimento da biopolítca, menciona que essa forma de controle opera com a ideia de que a "distribuição da espécie humana em grupos, a subdivisão da população em subgrupos e o estabelecimento de uma cesura biológica entre uns e outros" gera o racismo. Daí que, para Mbembe (2016), pensar a partir das proposições foucaultianas requer a compreensão de que o racismo é uma tecnologia utilizada para permitir o uso do biopoder ${ }^{9}$.

No que pese a questão de gênero, buscamos a noção de interseccionalidade ${ }^{10}$ na intenção de problematizar a discussão sobre a desigualdade social e a atividade física, pois tal noção nos permitiu discutir as diversas dimensões que diferenciam e determinam a condição da mulher.

Assim, ao compreender que os aspectos econômicos, políticos, culturais, físicos, influenciam significativamente a constituição das subjetividades e corporeidades femininas, discutimos a necessidade de considerar o lugar de enunciação que os diferentes marcadores sociais possuem, causando "impacto na forma como se ascende aos direitos e às oportunidades" (PEREIRA, 2018, p. 67-68).

Por fim, ao término da aula, deixamos com os(as) estudantes algumas perguntas para serem respondidas e apresentadas na aula posterior: refletir sobre a condição da trabalhadora explicitada na pesquisa de Mourão (1999) e responder se a mesma é sedentária; diante da rotina apresentada no relato da diarista, mencionar como ela faria para realizar os exercícios preconizados pela mídia; e, por fim, tecer as considerações sobre a condição de saúde da referida trabalhadora.

Cabe frisar que essa etapa do processo de aprendizagemensino foi baseada em Palma e Vilaça (2010) quando discutem as incongruências entre os valores das distintas medidas de sedentarismo, debatem a noção de fenômenos "não transmissíveis", sobretudo, no que se refere à adesão à prática regular de exercícios físicos:

\footnotetext{
${ }^{9}$ Nesse estudo, entendemos biopoder como um "conjunto dos mecanismos pelos quais aquilo que, na espécie humana, constitui suas características biológicas fundamentais, vai poder entrar numa política, numa estratégia política, numa estratégia geral do poder" (FOUCAULT, 2008a, p. 3).

10 A interseccionalidade é entendida como um posicionamento cunhado a partir da opressão da sociedade "cisheteropatriarcal" ao feminismo negro colocando um véu sobre a sobreposição de exclusões - raça, classe, gênero, dentre outras - que as afligem (COLLINS, 2017).
} 
No que tange à prática de atividade física, a partir principalmente do conhecimento com base na noção de causa e efeito, tem sido imputada ao indivíduo a culpa por sua condição sedentária, uma vez que o comportamento pessoal dependeria apenas do próprio sujeito para ser modificado (PALMA; VILAÇA, 2010 p. 111).

Portanto, ao problematizarmos a complexidade que envolve as desigualdades sociais e a ausência de direitos que garantam o acesso à atividade física, nos aproximamos da discussão dos autores supramencionados que entendem que a lógica neoliberal atua de modo a produzir um estado frágil que se isenta de sua reponsabilidade como regulador na relação da sociedade com a lógica do mercado.

$\mathrm{Na}$ quarta aula, o objetivo foi discutir os resultados das perguntas da aula anterior, contextualizando as respostas dos(as) estudantes, a partir dos conceitos apresentados nas discussões das três primeiras aulas.

Considerando a primeira questão (refletir sobre a condição da trabalhadora explicitada - Dona Maria - na pesquisa de Mourão (1999), respondendo se a empregada doméstica seria uma pessoa sedentária) realizada aos(às) estudantes no final da terceira aula, iniciamos o debate com uma rápida enquete com eles(as), na intenção de identificar o que o grupo pensava a respeito da condição da empregada doméstica mencionada na pesquisa.

Imediatamente, vinte e dois estudantes se posicionaram afirmando que não a consideravam sedentária, restando apenas um estudante com a assertiva de que a empregada doméstica seria sedentária devido à ausência de atividade física em sua rotina diária.

Diante das respostas dos(as) estudantes, reiniciamos o diálogo tendo as reflexões de Palma e Vilaça (2010) como base argumentativa, provocando outras reflexões em relação ao conceito de sedentarismo e, rapidamente, duas estudantes se manifestaram expressando suas percepções diante das provocações:

E: Ela faz atividade física todo dia no serviço dela.

L: Em casa, cuidando da casa, cuidando dos filhos.

Simultaneamente ao posicionamento de E. e L., outros(as) estudantes se posicionaram reiterando que as atividades realizadas pela Dona Maria ao longo de sua jornada de trabalho caminhada para ir ao trabalho e, posteriormente, para retornar a sua casa, as atividades laborais como doméstica e, em decorrência, como dona de casa após o trabalho -, eram atividades físicas, portanto, poderíamos considerar a empregada doméstica como uma pessoa ativa.

Nesse sentido, nos parece que a dialogicidade permitiu a reflexão sobre o mundo vivido: "Testemunhando objetivamente a história, mesmo a consciência ingênua acaba por despertar 
criticamente, para identificar-se como personagem que se ignorava e é chamada a assumir seu papel” (FREIRE, 2011, p. 4).

Diante do debate estabelecido, a segunda pergunta referente à rotina apresentada no relato da diarista - Como a Dona Maria realizaria os exercícios preconizados pela mídia? - foi problematizada no enredamento da pergunta anterior, visto que, ao refletir coletivamente sobre os horários, as atividades e a rotina laboral da empregada doméstica, o coletivo considerou que ela, apesar de não ter a possibilidade de cumprir com os preceitos estabelecidos pela mídia, a partir da proposição de exercícios físicos, não poderia ser considerada sedentária por realizar diversas atividades físicas.

Por fim, a última pergunta se referia às condições de saúde da referida trabalhadora (Dona Maria, em sua rotina, apresenta condições para obter saúde?) e as respostas convergiram para os seguintes aspectos: exercício, alimentação saudável, praticar esporte, não beber, não fumar, não se estressar, ter um dia de descanso, ir ao médico, fazer exames.

Assim, considerando as respostas dos(as) estudantes, que, em sua maioria, reproduzem a lógica neoliberal, pois operam na ótica que culpabiliza e responsabiliza o indivíduo pela ausência de saúde - praticar exercícios físicos, não beber, não fumar, dentre outras ações -, optamos por trazer ao debate os determinantes apresentados por Waissmann (2003) na aula anterior, que nos remeteram às desigualdades sociais e aos processos de colonização: capitalismo, colonialismo e patriarcado, que, neste estudo, assumem as condições de classe social (empregabilidade, renda, transporte urbano para ir e vir do trabalho, horas de sono e descanso; questão de raça) que interfere historicamente determinando a condição subalterna e excludente do negro na sociedade brasileira, por fim, a questão de gênero que diante do exemplo de Dona Maria emerge da dupla ou tripla jornada laboral a que mulher brasileira está submetida.

Na quinta aula, apresentamos inicialmente dois vídeos (“Outro olhar: Dia Nacional de Combate ao Sedentarismo"11 e o vídeo "Sedentarismo: não exercitar-se é um passo para adquirir doenças como obesidade e diabetes ${ }^{12 "}$ ) - no intuito de problematizar a noção de sedentarismo.

Vale salientar que, nesse momento, utilizamos como contraponto o artigo de Palma e Vilaça (2010), uma vez que os autores, ao problematizarem a noção de sedentarismo, explicam o problema de se trabalhar com o referido conceito, salientando que a literatura apresenta

\footnotetext{
${ }^{11} \mathrm{O}$ vídeo no formato de animação aborda o sedentarismo na infância. Disponível em: https://www.youtube.com/ watch? $\mathrm{v}=$ Xz5FKmcRRLg/.

${ }^{12}$ Vídeo do Ministério da Saúde abordando a inatividade física como fator importante para o tratamento de doenças não transmissíveis como obesidade, diabete e doenças cardíacas. Disponível em: https://www.youtube.com/ watch? $\mathrm{v}=\mathrm{KrGbM}-\mathrm{jnxAA}$.
} 
diferentes medidas para o sedentarismo, acarretando resultados díspares: "De fato, qualquer tentativa de definir o que seja 'sedentarismo' deverá esbarrar em sérios problemas. O conceito é vulgar, isto é, não é científico, uma vez que não pode ser apreendido e compreendido com precisão" (Idem, p. 107). Um fragmento do vídeo a seguir reflete a disparidade no conceito de sedentarismo, conforme mencionado por Palma e Vilaça (2010):

A pessoa que não realiza atividade física é uma pessoa sedentária [...] o ideal seria cinco vezes por semana durante mais de trinta minutos. Esses trinta minutos podem ser consecutivos ou não. O que seria atividade física? Atividade aeróbica: Qualquer atividade aeróbica: andar correr, pedalar, caminhar (SEDENTARISMO: não exercitar-se é um passo para adquirir doenças como obesidade e diabetes, 2017).

Outra atividade realizada na aula e que nos serviu para problematizar a relação exercício físico, atividade física e sedentarismo emergiu de uma proposição realizada em sala no final da quarta aula. Solicitamos a dois estudantes - voluntários (uma adolescente e um adolescente, ambos com 17 anos) - que no decorrer da semana anotassem o número de passos dados diariamente. Do mesmo modo, combinamos com a turma que solicitaria a um motorista de uma empresa de refrigerantes da região que realizasse a mesma contagem, nos possibilitando a comparação dos dados. Ressaltamos que o objetivo dessa aula foi apresentar um vídeo sobre sedentarismo, problematizando a saúde a partir dos depoimentos e das experiências (práticas corporais) dos(as) estudantes da turma (Ver objetivo da aula 5 no Quadro 1). Os depoimentos narravam o monitoramento das atividades diárias realizadas pelos(as) participantes no transcorrer de uma semana, utilizando o pedômetro (Liveup Contador de Passos e Calorias - ver anotações do estudante R.).

\footnotetext{
- 18/09/18: 11689 passos.

- 19/09/18: 11635 passos.

- 20/09/18: 8398 passos.

-21/09/18: 11440 passos.

- 22/09/18: 11.680 passos.

-23/09/18: 11.765 passos.
}

Anotações do número de passos do estudante R. no decorrer de uma semana:

Ao término da apresentação dos vídeos/depoimentos, ampliamos o diálogo utilizando a roda de conversa como metodologia pedagógica, visto que "o diálogo é um momento singular de partilha, porque pressupõe um exercício de escuta e fala" (MOURA; LIMA, 2015, p. 28).

Assim, a dinâmica estabelecida entre os vídeos, o artigo de Palma e Vilaça (2010), os depoimentos dos(as) estudantes e do motorista de caminhão e os debates dos(as) estudantes da turma, permitiram a constituição de uma rede de conversações que nos moveu em direção aos elementos que determinam ou influenciam a condição de saúde do trabalhador brasileiro: renda 
salarial, transporte público, o tempo de deslocamento para chegar ao trabalho, moradia, tempo disponível para lazer, moradia, dentre outros. Tal debate permitiu aos(às) estudantes o acesso à complexa rede que envolve os condicionantes da saúde no país.

Interessante perceber que, segundo Porto e Junqueira (2008), dez mil passos por dia seria a quantidade ideal para o indivíduo não ser considerado "sedentário", portanto, R. automaticamente estaria fora desta classificação, visto que ele realizou mais de dez mil passos no seu dia.

Diante de tal situação, perguntamos à turma se este estudante (R.) poderia ser considerado sedentário, mesmo tendo afirmado em seu depoimento que não vai à academia porque "não tem tempo" e nem condições financeiras, mas vai para a escola de bicicleta e quando sai do colégio trabalha na feira com seu pai, carregando caixotes. Tal condição nos auxiliou na ampliação da discussão na roda de conversa, pois durante o debate nos foi possível discutir o modo como as atividades realizadas pelas pessoas se altera de acordo com a classe social, o gênero, a idade, dentre outras.

Na sexta aula, no intuito de concluir a discussão em torno da temática da saúde, propomos à turma um trabalho em grupo, nos permitindo avaliar a construção do processo de ensino e aprendizagem.

Figura 4. Trabalho dos(as) estudantes - Conceito de Saúde

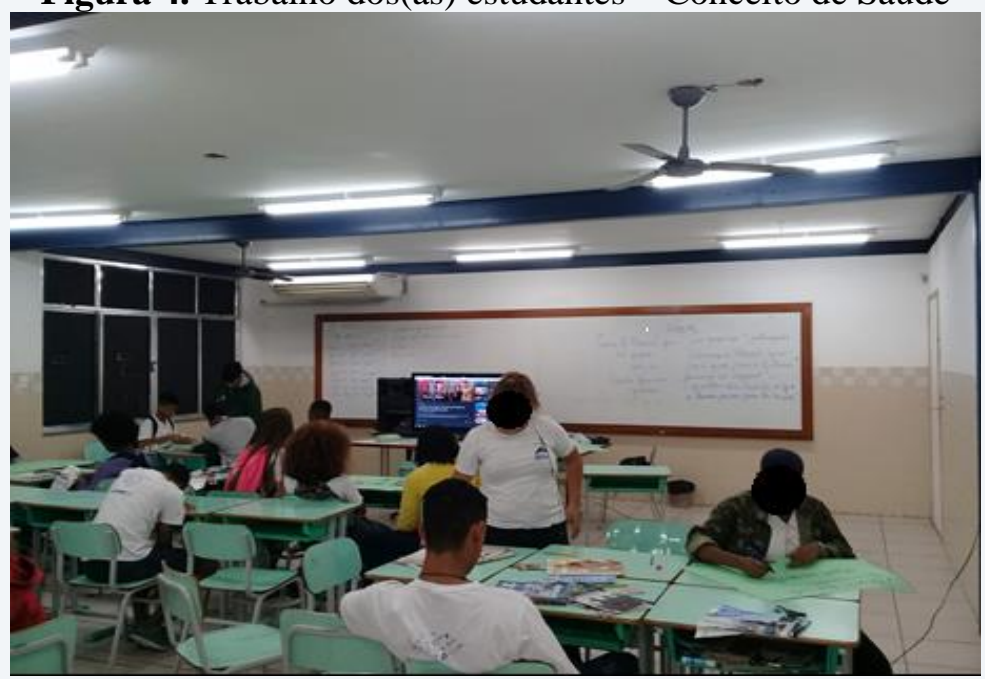

Fonte: Autoria Própria.

No momento que antecedeu à produção coletiva do trabalho (Figura 4), por meio da roda de conversa, solicitamos aos estudantes que identificassem os espaços em Volta Redonda onde percebessem a ampliação da noção de saúde e eles(as) mencionaram os seguintes espaços: Projeto Terceira Idade, Hospital do Idoso, Jovem Aprendiz, Parque Aquático da Secretaria de Esportes, Kartódromo, escolas, hospitais. 
Posteriormente, iniciamos a produção coletiva sobre saúde, utilizando imagens, visto que, entendemos que o imaginário colonial moderno nos últimos séculos credibilizou o conhecimento científico, a história e a grafia como únicas formas de saber válido.

Nessa linha de pensamento, no intuito de contrapor a referida lógica, optamos pelo uso da imagem, pois a "incredibilidade das alternativas é o reverso da indolência da vontade" (SANTOS, 2018, p. 215). Assim, ao privilegiar a iconografia nos aproximamos de Alves (2001) que, ao questionar a validade do pensamento moderno nos pergunta se haveria a possibilidade de literaturizar o conhecimento de modo a ressignifica-lo, bem como de Oliveira e Geraldi (2010) consideram que a imagem permite narrar o mundo percorrendo outros caminhos e desvelando diferentes saberes, fazeres, valores e emoções, conforme podemos perceber.

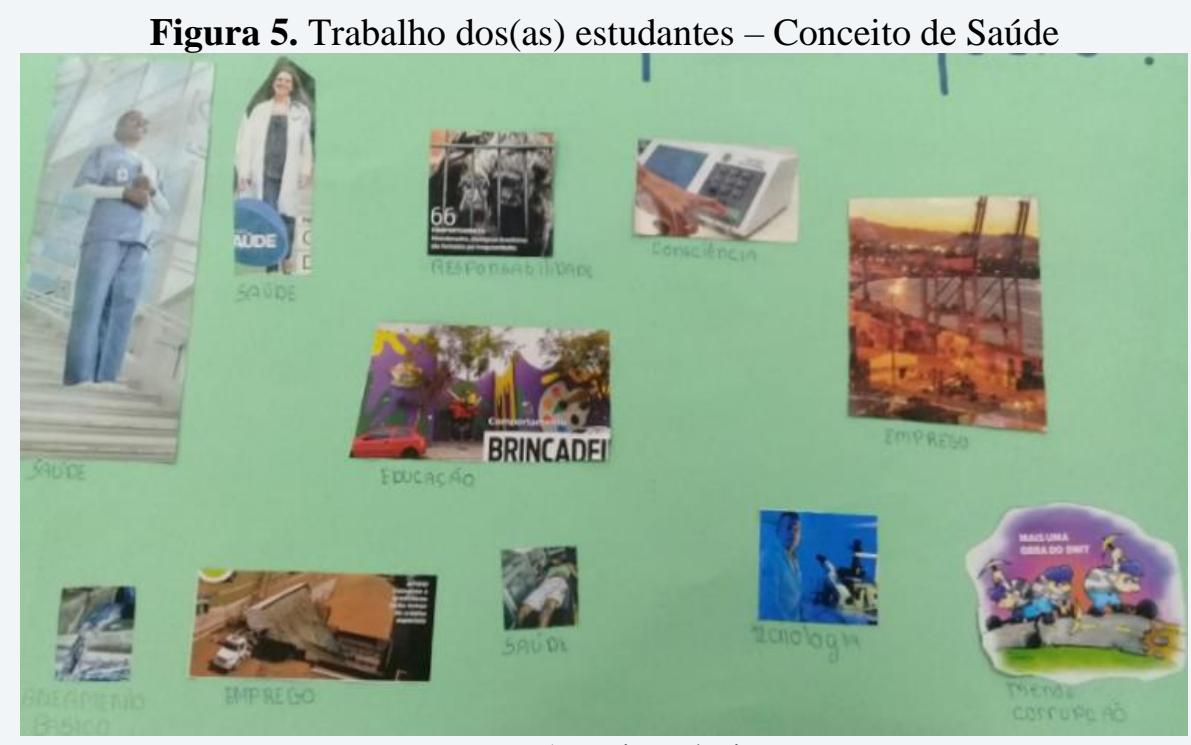

Fonte: Autoria Própria.

O trabalho nos remete à percepção de que a noção de saúde dos(as) estudantes não está restrita ao processo anatômico/biológico, mas se expande para além dele, pois as imagens utilizadas para narrar/expressar o modo como concebem a saúde nos parecem se constituir de maneira multifacetada após todo o processo, mas não antes da atividade proposta. Com relação ao uso da imagem como forma de narrar o mundo, Alves (2001) considera que:

Há assim, uma outra escritura a aprender: aquela que talvez se expresse com múltiplas linguagens (de sons, de imagens, de toques, de cheiros, etc.) e que, talvez, não possa ser chamada de "escrita"; que não obedeça à linearidade de exposição, mas que teça, ao ser feita, uma rede de múltiplos, diferentes e diversos fios (ALVES, 2001, p. 29-30). 
Figura 6. Trabalho dos(as) estudantes - Conceito de Saúde

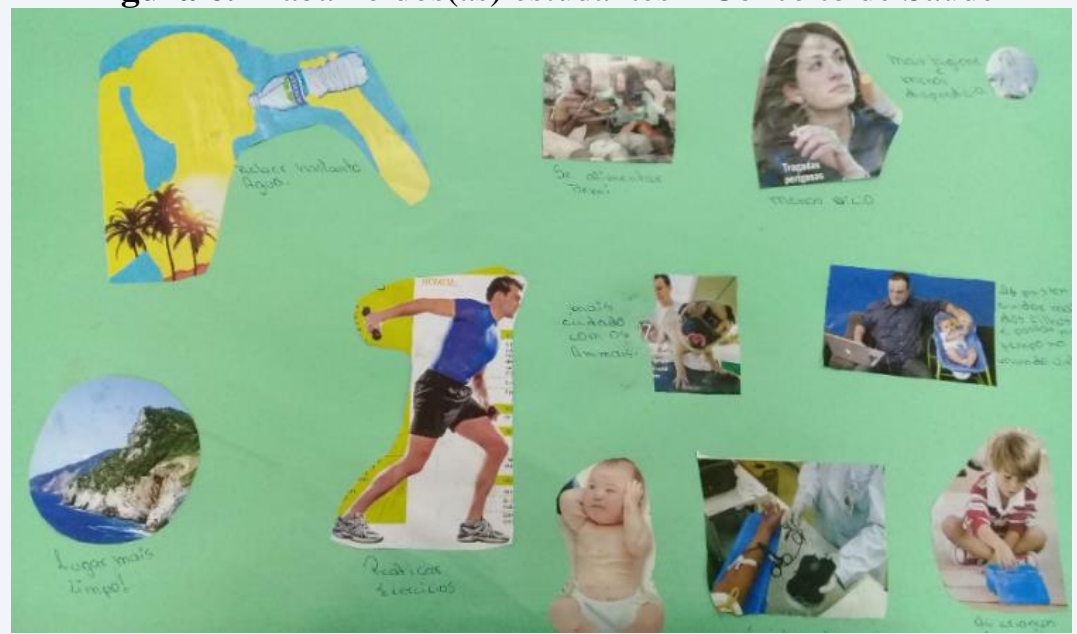

Fonte: Autoria Própria.

No segundo trabalho (Figura 6), novamente nos deparamos com uma noção de saúde que não está restrita à ótica anatômica ou ao exercício físico, pois encontramos os(as) estudantes que narram outros aspectos interferindo ou determinando no modo como as pessoas são impactadas pelo mundo de modo a adquirir ou a prejudicar o estado saudável de um ser humano.

Para finalizar, torna-se relevante ressaltar que não tivemos a intenção de estabelecer, com o trabalho avaliativo supramencionado, um caminho certo ou errado, mas de propiciar, conforme pressupõe a noção de tessitura de conhecimentos em redes, um espaço de diálogo e de construção coletiva, pois admitimos que tais saberes se tecem no emaranhado das redes individuais e coletivas em que os estudantes estão imersos, não tendo, desse modo, "origem nem desenvolvimento localizáveis, prioridades hierárquicas, previsibilidade ou obrigatoriedade de rota (OLIVEIRA, 2012, p. 68).

\section{Considerações Finais}

Considerando que o objetivo do trabalho foi visibilizar o modo como os(as) estudantes pensam a saúde, estabelecendo um diálogo a partir das questões singulares que se apresentam na interface entre a escola e a comunidade onde está inserida, ressaltamos que: a) foi possível promover um espaço de dialogicidade e conflito epistemológico entre os(as) estudantes utilizando outras fontes para além de artigos científicos; b) a sequência pedagógica desenvolvida propiciou a construção de saberes que emergiu da horizontalização dos conhecimentos trazidos ao chão da escola; c) artigos teóricos propostos, os vídeos, as imagens retiradas das redes sociais, as imagens utilizadas pelos(as) estudantes, as experiências promovidas com alguns(mas) estudantes promoveram momentos de reflexões coletivas, 
contribuindo com a construção de conhecimentos no âmbito da saúde, o que pode ser percebido na confecção do trabalho final da turma.

Assim, salientamos que a experiência social desenvolvida em uma escola pública do município de Volta Redonda se aproxima da razão cosmopolita (SANTOS, 2018), porque se volta contra o desperdício da experiência, que apoiado na racionalidade moderna defende que a única forma de conhecimento válido é o produzido pela rigorosidade científica.

Enfim, ao considerarmos que há uma riqueza inesgotável no mundo que está a ser desperdiçada, o que buscamos salientar é que não concebemos essa proposta didática como modelo a ser seguido, mas como uma prática sociocultural construída em redes de subjetividade e que promove a ruptura com a hierarquização de conhecimentos valorizando e horizontalizando diversos modos de compreensão do mundo.

\section{REFERÊNCIAS}

ALVES, Nilda. Decifrando o pergaminho: o cotidiano das escolas nas lógicas das redes cotidianas. In: OLIVEIRA, I B.; ALVES, N. (orgs.). Pesquisa no/do cotidiano das escolas: sobre redes de saberes. Rio de Janeiro: DP\&A, 2001.

ALVES, Nilda. Sobre movimentos das pesquisas nos/dos/com os cotidianos. Teias: Rio de Janeiro, ano 4, n. 7-8, jan./dez. 2003.

BENJAMIN, Walter. Obras escolhidas: magia e técnica, arte e política. São Paulo: Editora Brasiliense, 1994.

CARGNIN, Miria Trentin. Programa saúde na escola: uma estratégia de governamento. 2015. 191 f. Tese (Doutorado em Educação) - Universidade do Vale do Rio dos Sinos, Programa de Pós-Graduação em Educação, São Leopoldo, Rio Grande do Sul, 2015.

CERTEAU, Michel. A invenção do cotidiano. V.1: artes de fazer. Petrópolis: Vozes, 1994.

CHEIK, Nadia Carla. et al. Efeitos do exercício físico e da atividade física na depressão e ansiedade em indivíduos idosos. Revista Brasileira de Ciência e Movimento, [s.l.], v. 11, n. 3, p. 45-52, 2008.

COLLINS, Patricia Hill. Se perdeu na tradução? Feminismo negro, interseccionalidade e política emancipatória. Parágrafo, [s.1.], v. 5, n. 1, p. 6-17, 2017.

FASANELLO, Marina Tarnowski; NUNES, João Arriscado; PORTO, Marcelo Firpo de Souza. Metodologias colaborativas não extrativistas e comunicação: articulando criativamente saberes e sentidos para a emancipação social. Revista Eletrônica Comunicação,

Informação e Inovação em Saúde, [s.1.], v. 12, n. 4, p. 396-414, out./dez. 2018. 
FERNANDES DE FREITAS, Fabiana; DE CARVALHO, Yara Maria; MONTEIRO MENDES, Valéria. Educação Física e Saúde: aproximações com a "clínica ampliada”. Revista Brasileira de Ciências do Esporte, [s.1.], v. 35, n. 3, 2013.

FREIRE, Paulo. Pedagogia do oprimido. 50. ed. São Paulo: Paz e Terra, 2011.

FOUCAULT, Michel. Segurança, território, população: Curso dado no Collège de France (1977-1978). São Paulo: Martins Fontes, 2008.

LIBÂNEO, José. Carlos. As Teorias Pedagógicas Modernas Revisitadas pelo Debate Contemporâneo na Educação. In: LIBÂNEO, José. Carlos; SANTOS, Akiko. Educação na era do conhecimento em rede e transdiciplinaridade. Campinas: Ed. Alinea, 2005.

MARTINS, Paulo Henrique. Epistemologias do Sul e seus Impactos sobre as ações e as Políticas em Saúde no Brasil. Revista Ensaios e \& Diálogos em Saúde Coletiva, [s.1.], n. 3, 2016.

MBEMBE, Achile. Necropolítica. PPGAV/EBA/UFRJ. Arte \& Ensaios, [s.1.], n. 32, dez. 2016.

MENESES, Maria Paula. “Quando não há problemas, estamos de boa saúde, sem azar nem nada": para uma concepção emancipatória de saúde e das medicinas. In: SANTOS,

Boaventura de Sousa (org.). Semear outras soluções: os caminhos da biodiversidade e dos conhecimentos rivais. Rio de Janeiro: Civilização, 2005. p. 423-468.

MILLS, Charles Wright. A imaginação sociológica. Rio de Janeiro: Zahar, 1975.

MOLLO, Elisa Canqui. El vivir bien, una propuesta de los pueblos indígenas a la discusión sobre el desarrollo. Obets. Revista de Ciencias Sociales, [s.l.], v. 6, n. 1, p. 19-33, 2011.

MOURA, Adriana Borges Ferro; LIMA, Maria da Glória Soares Barbosa. A Reinvenção da Roda: Roda de Conversa, um instrumento metodológico possível. Interfaces da Educação, [s.1.], v. 5, n. 15, p. 24-35, 2015.

MOURÃO, Ludmila. Representação social da relação do trabalho feminino da diarista com as opções de lazer na comunidade de Queimados. Motus Corporis, [s.1.], v. 6, n. 2, p. 52-72, 1999.

OLIVEIRA, Inês Barbosa. Aprendendo nos/dos/com os cotidianos a ver/ler/ouvir/sentir o mundo. Educação \& Sociedade, [s.l.], v. 28, n. 98, p. 47-72, 2007.

OLIVEIRA, Inês Barbosa. O currículo como criação cotidiana. Petrópolis, RJ: DP et Alii; Rio de Janeiro: FAPERJ, 2012.

OLIVEIRA, Inês Barbosa; GERALDI, João Wanderley. Narrativas: outros conhecimentos, outras formas de expressão. In: OLIVEIRA, I. B. (org.). Narrativas: outros conhecimentos, outras formas de expressão. Petrópolis, RJ: DP et Alii, 2010. p. 13-28.

OLIVEIRA, Inês Barbosa; REIS, Graça. Pesquisas com Formação de Professorxs: rodas de conversa e narrativas de experiências. 1. ed. Petrópolis, RJ: DP et Alii, 2017. 
PALMA, Alexandre; VILAÇA, Murilo Mariano. O sedentarismo da epidemiologia. Revista Brasileira de Ciências do Esporte, [s.l.], v. 31, n. 2, p. 105-119, 2010.

PALMA, Alexandre et al. Culto ao corpo e exposição de produtos na mídia especializada em estética e saúde. Movimento (ESEFID/UFRGS), [s.1.], v. 16, n. 1, p. 31-51, 2010.

PEREIRA, Camila Santos. Interseccionalidade e lugar de fala no trabalho em Direitos Humanos. In: ROSA, Marcus Vinicius de Freitas; NARDI, Henrique Caetano; MACHADO, Paula Sandrini; SILVEIRA, Raquel da Silva. Políticas públicas, relações de gênero, diversidade sexual e raça na perspectiva interseccional. 1. ed. Porto Alegre: Secco Editora, 2018.

POLLAK, Michael. A gestão do indizível. WebMosaica, v.2, n 1, jan.-jun. 2010.

PORTO, Luiz Guilherme Grossi; JUNQUEIRA JR, Luiz Fernando. Adesão a um programa de atividade física baseado no incremento do número de passos diários, por homens saudáveis sedentários. Revista Brasileira de Ciência e Movimento, [s.1.], v. 16, n. 2, p. 41-48, 2009.

RAGO, Margareth. Narcisismo, sujeição e estéticas da existência. Verve, São Paulo, v. 9, n. 9, p. 236-250, 2006,

SANTOS, Boaventura de Sousa. A Gramática do Tempo: para uma nova cultura política. São Paulo: Cortez, 2010.

SANTOS, Boaventura de Sousa. Construindo as Epistemologias do Sul: Antologia

Esencial. Volume I: Para um pensamento alternativo de alternativas. 1. ed. Ciudad Autónoma de Buenos Aires: CLACSO, 2018.

SEDENTARISMO: não exercitar-se é um passo para adquirir doenças como obesidade e diabetes. Ministério da Saúde. [S.1.: s.n.], 2017 (3m32s). Disponível em:

https://www.youtube.com/watch?v=KrGbM-jnxAA. Acesso em: 22 out. 2019.

SILVA JÚNIOR, Aristides José. Programa saúde na escola: limites e possibilidades intersetoriais. Interface: Comunicação, Saúde, Educação, [s.l.], v. 18, n. 51, p. 799, 2014.

WAISSMANN, Willian. Desigualdade Social e Atividade física. In: BAGRICHEVSKY, Marcos. PALMA, Alexandre. ESTEVÃO, Adriana. (orgs.). A saúde em debate na educação física. Blumenau: Edibes, 2003.

\section{SOBRE OS AUTORES:}

\section{Cinthia Emerenciana de Almeida}

Mestranda em Ensino em Ciências da Saúde e Meio ambiente; UniFOA; Programa de Mestrado Profissional em Ensino em Ciências da Saúde e Meio ambiente; Laboratório Interdisciplinar de Estudos em Educação Física e Práticas Corporais. E-mail: cinthiamerem @yahoo.com.br.

iD http://orcid.org/0000-0001-5665-7034 


\section{Alexandre Palma de Oliveira}

Doutor em Saúde Pública pela Fundação Oswaldo Cruz; UFRJ; Programa de Pós-Graduação Stricto Sensu em Educação Física da Universidade Federal do Rio de Janeiro; Laboratório integrado de Pesquisa em Exercício, Biomedicina, e Saúde Coletiva. E-mail: palma_alexandre@yahoo.com.br.

iD http://orcid.org/0000-0002-4679-9191

\section{Marcelo Paraiso Alves}

Doutor em Educação, UFF; UniFOA/IFRJ; Programa de Mestrado profissional em Ensino em Ciências da Saúde e do Meio Ambiente; Laboratório Interdisciplinar de Estudos em Educação Física e Práticas Corporais; E-mail: marceloparaiso@outlook.com.

iD http://orcid.org/0000-0002-6236-3224

Recebido em 17 de abril de 2020 Aprovado em 13 de agosto de 2020 Publicado em 07 de setembro de 2020 